\title{
Inaccuracy and delay in decision making in paediatric resuscitation, and a proposed reference chart to reduce error
}

\author{
Peter A Oakley
}

\begin{abstract}
Several surveys have noted the poor performance of junior hospital doctors in simulated cardiorespiratory arrest in adults. A further survey was undertaken to investigate inaccuracy and delay in the resuscitation of children. The results suggested that inaccuracy was a greater problem than delay.

Because of the variation in size of children and the comparative infrequency of cardiorespiratory arrest in this age group a simple, versatile, and readily available reference chart is needed to aid rapid and accurate decisions.
\end{abstract}

\section{Introduction}

Recent surveys on resuscitation have focused mainly on adults rather than children and on practical skills rather than decision making..$^{1-3}$ In children the main causes of cardiorespiratory arrest are different, and there are important differences in physiology and pharmacology. Two other factors, however, contribute substantially to the problems of decision making in children. The first is the variation in their size, which leads to difficulty in selecting the appropriate drug dosage, especially if the child's weight is not known. Secondly, as cardiorespiratory arrest is an infrequent occurrence, except in the newborn, each doctor's continued experience of it is limited and there is a tendency to forget recommended doses.

The following survey was undertaken to see whether inaccuracy and delay were serious problems in the use of drugs and equipment.

\section{Subjects and methods}

The survey included 34 junior hospital doctors (19 senior house officers, nine registrars, six senior registrars) from the specialties of paediatrics, anaesthesia, and accident and emergency medicine. Each doctor was asked a series of questions relating to the resuscitation of children in the accident and emergency department. Fifteen questions were asked in random order and with timed answers. Three representative children's ages were used ( 3 months, 3 years, and 7 years) and the following five questions repeated for each age:

In a cardiorespiratory arrest in a child (aged 3 months, 3 years, or 7 years)

What size endotracheal tube would you choose?

What dose of adrenaline would you give in asystole?

What dose of atropine would you give for a persistent bradycardia despite good oxygenation?

What dose of bicarbonate would you give in a prolonged arrest with no blood gas monitoring facilities available?

How many joules would you use to defibrillate in ventricular fibrillation

A Psion Organiser II pocket microcomputer was used to generate the 15 questions in random order, and the answers were timed by using the computer's internal clock. Age was used in the questions, as this is often known in the accident and emergency department, whereas weight may not readily be available.

In order to assess accuracy standard answers were defined, based on the Resuscitation Council guidelines. ${ }^{4}$ Where the guidelines refer to doses per $\mathrm{kg}$ the 50 th centile (median) weight at the particular age was used to calculate the standard answer. Two ranges of "acceptable answers" were defined for each question, as shown in tables I-V. The second range was particularly generous, allowing four sizes of endotracheal tube (from two sizes too small to one size too large) and a fourfold range of answers for drug and defibrillation dosages (from half to twice the standard answer).
Bristol Royal Hospital for Sick Children, Bristol BS2 8BJ

Peter A Oakley, FFARCS, registrar in anaesthesia

Correspondence to: Dr Oakley, Department of Emergency Services, Sunnybrook Medical Centre, 2075 Bayview Avenue, Toronto, Ontario, Canada M4N 3M5
TABLE I-Endotracheal tube size
$\%$ Of junior doctors unable to give an answer

Range of answers given ( $\mathrm{ml}$ of $1 / 10000$ )

$\%$ Of answers lying between Resuscitation Council guidelines for 10th and 90th centiles of weight $\%$ Of answers lying between half and twice Resuscitation Council guidelines for 50th centile of weight Maximum time to answer(s)

Median time to answer (s)

\begin{tabular}{ccc}
\multicolumn{3}{c}{ Age of child } \\
\hline 3 Months & 3 Years & 7 Years \\
\hline 24 & 21 & 21 \\
$1 \cdot 5-4 \cdot 5$ & $3 \cdot 0 \cdot 5 \cdot 5$ & $3 \cdot 5 \cdot 7 \cdot 5$ \\
65 & 56 & 44 \\
68 & 68 & 68 \\
22 & 33 & 28 \\
8 & 8 & 9
\end{tabular}

TABLE II-Adrenaline dosage 


\begin{tabular}{|c|c|c|c|}
\hline & \multicolumn{3}{|c|}{ Age of child } \\
\hline & 3 Months & 3 Years & 7 Years \\
\hline $\begin{array}{l}\text { \% Of junior doctors unable to give an answer } \\
\text { Range of answers given (mg) } \\
\% \text { Of answers lying between Resuscitation Council guidelines for } 10 \text { th and } 90 \text { th centiles of weight } \\
\% \text { Of answers lying between half and twice Resuscitation Council guidelines for } 50 \text { th centile of weight } \\
\text { Maximum time to answer }(\mathrm{s}) \\
\text { Median time to answer }(\mathrm{s})\end{array}$ & $\begin{array}{l}29 \\
0.05-0.5 \\
32 \\
59 \\
26 \\
11\end{array}$ & $\begin{array}{l}29 \\
0 \cdot 1-1 \cdot 5 \\
21 \\
53 \\
40 \\
10\end{array}$ & $\begin{array}{l}29 \\
0 \cdot 1-2 \cdot 0 \\
32 \\
47 \\
103 \\
9\end{array}$ \\
\hline
\end{tabular}

TABLE IV-Bicarbonate dosage

\begin{tabular}{|c|c|c|c|}
\hline & \multicolumn{3}{|c|}{ Age of child } \\
\hline & 3 Months & 3 Years & 7 Years \\
\hline $\begin{array}{l}\text { \% Of junior doctors unable to give an answer } \\
\text { Range of answers given (mmol) } \\
\% \text { Of answers lying between Resuscitation Council guidelines for } 10 \text { th and } 90 \text { th centiles of weight } \\
\% \text { Of answers lying between half and twice Resuscitation Council guidelines for } 50 \text { th centile of weight } \\
\text { Maximum time to answer (s) } \\
\text { Median time to answer (s) }\end{array}$ & $\begin{array}{l}21 \\
0 \cdot 5-25 \\
29 \\
65 \\
39 \\
9\end{array}$ & $\begin{array}{l}15 \\
0 \cdot 5-50 \\
26 \\
65 \\
45 \\
14\end{array}$ & $\begin{array}{c}15 \\
1-100 \\
44 \\
53 \\
77 \\
9\end{array}$ \\
\hline
\end{tabular}

The relation between accuracy and the speed of answer was investigated by using Spearman rank correlation tests.

\section{Results}

Tables I-V give the results. There was no significant correlation between accuracy and the speed of answer

Proposed reference chart to

improve performance

Endotracheal tube
\begin{tabular}{|c|c|}
\hline $\begin{array}{c}\text { Length } \\
(\mathrm{cm})\end{array}$ & $\begin{array}{c}\text { Internal } \\
\text { diameter } \\
(\mathrm{mm})\end{array}$ \\
\hline $18-21$ & $7.5-8.0$ \\
\hline 18 & 7.0 \\
\hline 17 & 6.5 \\
\hline 16 & 6.0 \\
\hline 15 & 5.5 \\
\hline 14 & 5.0 \\
\hline 13 & 4.5 \\
\hline 12 & 4.0 \\
\hline 10 & 3.5 \\
\hline
\end{tabular}

\section{Paediatric resuscitation chart}

Length $(\mathrm{cm})$

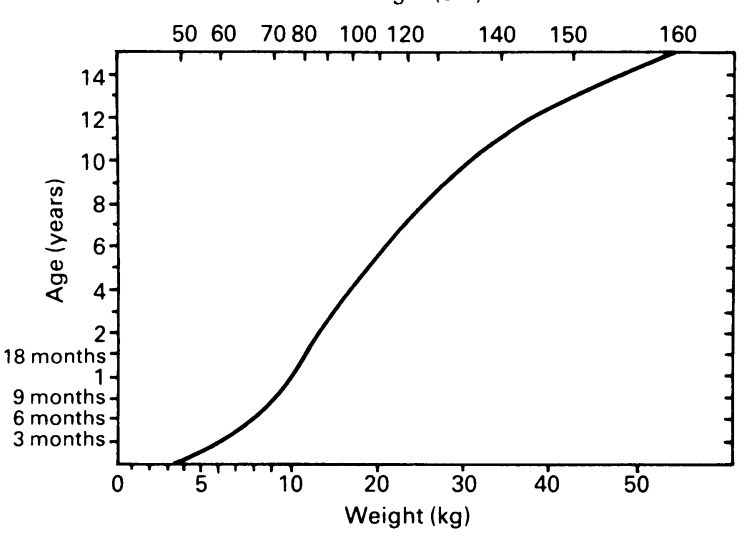

\begin{tabular}{|c|c|c|c|c|c|c|}
\hline $\begin{array}{l}\text { Adrenaline ( } \mathrm{ml} \text { of } 1 / 10000) \\
\text { intravenous or endotracheal }\end{array}$ & 0.5 & 1 & 2 & 3 & 4 & 5 \\
\hline $\begin{array}{l}\text { Atropine (mg) } \\
\text { intravenous or endotracheal }\end{array}$ & $0 \cdot 1$ & 0.2 & 0.4 & 0.6 & 0.6 & 0.6 \\
\hline $\begin{array}{l}\text { Bicarbonate }(\mathrm{ml} \text { of } 8.4 \%) \\
\text { intravenous }\end{array}$ & 5 & 10 & 20 & 30 & 40 & 50 \\
\hline $\begin{array}{l}\text { Calcium chloride }(\mathrm{mmol})^{*} \\
\text { intravenous }\end{array}$ & 1 & 2 & 4 & 6 & 8 & 10 \\
\hline $\begin{array}{r}\text { Diazepam (mg) intravenous } \\
\text { per rectum }\end{array}$ & $\begin{array}{l}1.25 \\
2.5\end{array}$ & $\begin{array}{l}2 \cdot 5 \\
5\end{array}$ & $\begin{array}{r}5 \\
10\end{array}$ & $\begin{array}{l}7 \cdot 5 \\
-\end{array}$ & $\begin{array}{l}10 \\
-\end{array}$ & 10 \\
\hline $\begin{array}{l}\text { Glucose ( } \mathrm{ml} \text { of } 50 \% \text { ) } \\
\text { intravenous }\end{array}$ & 10 & 20 & 40 & 60 & 80 & 100 \\
\hline $\begin{array}{l}\text { Lignocaine (mg) } \\
\text { intravenous or endotracheal }\end{array}$ & 5 & 10 & 20 & 30 & 40 & 50 \\
\hline $\begin{array}{l}\text { Salbutamol }(\mu \mathrm{g}) \\
\text { intravenous }\end{array}$ & 25 & 50 & 100 & 150 & 200 & 250 \\
\hline Initial DC defibrillation $(\mathrm{J})$ & 10 & 20 & 40 & 60 & 80 & 100 \\
\hline $\begin{array}{l}\text { Initial fluid infusion in } \\
\text { hypovolaemic shock (ml) }\end{array}$ & 50 & 100 & 200 & 300 & 400 & 500 \\
\hline
\end{tabular}

* One millilitre calcium chloride $1 \mathrm{mmol} / \mathrm{ml} \equiv 1.5 \mathrm{ml}$ calcium chloride $10 \% \equiv 4.5 \mathrm{ml}$ calcium gluconate $10 \%$ except for endotracheal tube size in 7 year olds, for which the Spearman rank correlation coefficient was $+0 \cdot 62$.

\section{Discussion}

In general inaccuracy was a greater problem than delay. This was most apparent for the dosage of adrenaline, for which there was enormous variation in the answers given. Some junior doctors answered in $\mathrm{ml}$ of $1 / 10000$, others in $\mathrm{mg}, \mu \mathrm{g}$, or $\mathrm{ml}$ of $1 / 1000$. The answers were converted to the equivalent in $\mathrm{ml}$ of $1 / 10000$ for comparison, yielding a range of answers extending over three orders of magnitude. One in five or fewer answered within the 10th to 90 th centile range and fewer than half within the generous range of half to twice the standard answer.

The most accurate answers were for endotracheal tube size, especially in the infant. Two out of three doctors answered within the range of two tube sizes too small to one size too large at all three ages. The proportion unable to give any answer varied from over one in four for some questions - for example, atropine - to less than one in 10 for others-for example, defibrillation. The median time to answer ranged from six to 14 seconds and averaged less than 10 seconds. That half the answers were given in this time scale suggests that delay was not a serious problem. Some individual answers were slow, however, the maximum time to answer being 103 seconds.

Apart from the single significant positive correlation for endotracheal tube size in 7 year olds there was no evidence of any particular relation between accuracy and the speed of answer.

There were some differences among the three groups of doctors. For example, most of those unable to give an answer were casualty officers, though many paediatricians were unfamiliar with atropine dosage; none of the anaesthetists failed to give an answer. There were erratic answers in all the groups, but making quantitative comparisons among them was not justified, as the doctors were not of equivalent experience or seniority. In general registrars and senior registrars were more accurate than senior house officers.

In view of the considerable inaccuracy disclosed by the results it is worth considering the use of a simple reference chart to improve performance. The figure shows one such chart. The graph represents age plotted against weight for the 50th centile boy-girl average. To the left are shown dimensions of endotracheal tubes, which correlate well with age. Below is a table showing various drug doses for use in cardio- 


\begin{tabular}{|c|c|c|c|}
\hline & \multicolumn{3}{|c|}{ Age of child } \\
\hline & 3 Months & 3 Years & 7 Years \\
\hline$\%$ Of junior doctors unable to give an answer & 15 & 12 & 9 \\
\hline Range of answers given $(\mathrm{J})$ & $5-50$ & $10-100$ & $10-100$ \\
\hline$\%$ Of answers lying between Resuscitation Council guidelines for 10th and 90 th centiles of weight & 24 & 21 & 38 \\
\hline$\%$ Of answers lying between half and twice Resuscitation Council guidelines for 50 th centile of weight & 44 & 65 & 59 \\
\hline Maximum time to answer $(\mathrm{s})$ & 32 & 16 & 18 \\
\hline Median time to answer (s) & 8 & 6 & 6 \\
\hline
\end{tabular}

respiratory arrest or other urgent conditions. Also included are defibrillator settings and suggestions for initial fluid infusion in hypovolaemia. The list is brief for simplicity but could easily be extended for particular purposes. The doses comply with the present Resuscitation Council guidelines. If the weight is already known drug dosage may be estimated by moving directly downwards from the weight axis. If age but not weight is known dosage may be estimated by tracing across the graph and then down to the dose. If neither is known a rapid stretched out length may be measured with a tape measure and the non-linear scale above the graph used to estimate drug dosage. The chart may be made large enough to see from the resuscitation trolley or small enough to fit the pocket. Furthermore, nursing staff could use it to prepare drugs and equipment in advance of their request.

In conclusion, the variation in size of children and the comparative infrequency of cardiorespiratory arrest in this age group require some form of simple, versatile, and readily available reference chart if rapid and accurate decisions are to be made.

I thank Dr P J F Baskett, Dr A M S Black, and the consultants at the Bristol Royal Hospital for Sick Children for their helpful advice.

An A2 size poster of the paediatric resuscitation chart is available from the Publishing Department, British Medical fournal, $B M A$ House, Tavistock Square, London WC1H $9 f R$ price £3.50, including post and packing (overseas $\$ 4.50$ or US\$9). Single copies of a postcard version of the chart are also available free from the same address on receipt of an A5 size stamped addressed envelope $(16 \times 24 \mathrm{~cm}, 6 \times 9$ in $)$. For bulk orders please write to the Book Department.

1 Lowenstein SR, Libby LS, Mountain RD, Hansbrough JF, Hill DM, Scoggin $\mathrm{CH}$. Cardiopulmonary resuscitation by medical and surgical house officers. CH. Cardiopulmonary 1981 ;ii:679-81.

2 Casey WF. Cardiopulmonary resuscitation: a survey of standards among junio hospital doctors. IR Soc Med 1984;77:921-4.

3 Skinner DV, Camm AJ, Miles S. Cardiopulmonary resuscitation skills of preregistration house officers. $\mathrm{Br}$ Med $\mathcal{J}$ 1985;290:1549-50.

4 Zideman DA. Resuscitation of infants and children. BrMed $\mathcal{f} 1986$;292:1584-8.

(Accepted 20 May 1988)

\title{
Psychiatric morbidity of a long stay hospital population with chronic schizophrenia and implications for future community care
}

\author{
D A Curson, M Patel, P F Liddle, T R E Barnes
}

Charter Clinic Chelsea, London SW3 4PB

D A Curson, $\mathrm{MRCPSYCH}$, medical director

\section{Shenley Hospital,} Hertfordshire

M Patel, MRCPSYCH, clinical assistant

\section{Charing Cross and Westminster Medical School, London P F Liddle, MRCPSYCH, senior lecturer \\ T R E Barnes, MRCPSYCH, senior lecturer}

Correspondence to: Dr Curson.

\begin{abstract}
In the United Kingdom there are plans to close most mental hospitals over the next $\mathbf{1 0}$ years. There is continuing uncertainty about the effectiveness of community psychiatric services that will be expected to cope with mental hospital inpatients after discharge, most of whom have schizophrenia. A survey was conducted to assess the severity of illness among such patients and implications for their future care. All 222 patients in non-psychogeriatric long stay wards of a mental hospital who met research diagnostic criteria for schizophrenia were interviewed by two psychiatrists with the comprehensive psychopathological rating scale to establish the prevalence of psychiatric symptomatology. A complete interview was not possible for 28 patients, mainly for reasons related to their schizophrenia. Despite energetic pharmacological and social treatments almost half of the 194 patients interviewed had enduring florid psychotic symptoms that presented as one or more delusions or auditory hallucinations, or both, and a sizable proportion showed behaviour that would set them apart in a community setting.

The results illustrate a problem that is still imperfectly understood by policy makers and administrators in central and local government and in health authorities who are responsible for planning and implementing services for psychiatric care in the community.
\end{abstract}

\section{Introduction}

In Europe and North America discharge of patients with chronic schizophrenia from mental hospitals began in the 1950s, before the widespread use of antipsychotic drug treatment. Avoiding admission, or early discharge, combined with domestic and industrial rehabilitation in open hospitals may prevent the accumulation of long stay "institutionalised" patients and allow a proportion of them to return to full participation in community life. ${ }^{1}$ The "therapeutic community" movement, ${ }^{2}$ best seen as an ideology rather than a therapeutic theory, did not originate in mental hospitals but spread to them later and, along with concern about institutional neurosis, ${ }^{3}$ the social breakdown syndrome, ${ }^{4}$ and asylums, ${ }^{5}$ had a considerable impact socially and politically. Thus the community care movement was born. In patients with chronic schizophrenia the success of such care depends on the validity of sociological theories about the causes of defect states; the effectiveness of new drug treatments in alleviating the acute and often bizarre symptoms of mental illness; the patients' compliance with both drug and social treatments; and the provision of suitably staffed amenities such as day hospitals, day centres, industrial units, and local hostels.

Generally the many thousands of patients with schizophrenia discharged from long stay wards in mental hospitals over the past quarter of a century have been those least impaired and most responsive to drug and social treatments. In the light of continuing uncertainty about the efficacy and effectiveness of community psychiatric services ${ }^{6}$ we describe a recent survey of an entire population of long stay patients with chronic schizophrenia in Horton Hospital, Epsom, a hospital scheduled to close within the next 10 years. 